\title{
Role and mechanism of the alkylglycerone phosphate synthase in suppressing the invasion potential of human glioma and hepatic carcinoma cells in vitro
}

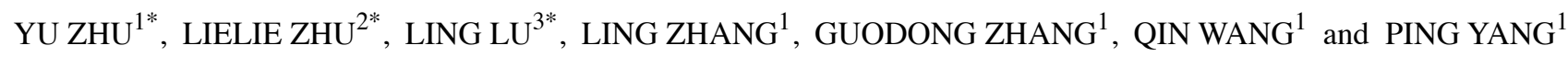 \\ ${ }^{1}$ Department of Clinical Laboratory, Tianjin Huan Hu Hospital, Tianjin Key Laboratory of Cerebral Vessels and \\ Neural Degeneration, Tianjin 300060; ${ }^{2}$ The Second Affiliated Hospital of Wenzhou Medical University, \\ Wenzhou, Zhejiang 325027; ${ }^{3}$ Graduate School of Tianjin Medical University, Tianjin 300070, P.R. China
}

Received March 6, 2014; Accepted April 29, 2014

DOI: $10.3892 /$ or.2014.3189

\begin{abstract}
Ether lipids have been implicated in the exacerbation of human tumors. Accumulating evidence suggests that the alkylglycerone phosphate synthase (AGPS) is involved in the suppression of some types of tumor. However, the role and molecular mechanism of AGPS in the invasion of human glioma and hepatic carcinoma remain unclear. In the present study, using AGPS-knockdown human glioma U87 and hepatic carcinoma HepG2 cell lines, we explored the role of AGPS, as well as its molecular mechanism, in invasion in vitro. It was demonstrated that silencing AGPS expression resulted in a decreased expression of cellular lipids such as LPA, LPAe and PGE2, adhesion, invasion potential and arrested cell cycle in tumor cells. The expression of invasion-related genes such as MMP-2/9,E-cadherin and CD44 showed marked changes in AGPS-knockdown cells. In addition, we found that AGPS regulated the activity of the MAPK pathway, as well as the transcriptional activity of Twist, AP-1, and Snail. The results demonstrated that AGPS negatively regulated the invasion potential of glioma and hepatic carcinoma cells by modulating the expression of relevant genes and activity of the MAPK pathway. Therefore, AGPS may be a potential glioma and hepatic carcinoma therapeutic target.
\end{abstract}

\section{Introduction}

The incidence rates of glioma and hepatic carcinoma increase annually in China and invasion suppression is key to clinical

Correspondence to: Dr Lielie Zhu, The Second Affiliated Hospital of Wenzhou Medical University, Wenzhou, Zhejiang 325027, P.R. China

E-mail: zhulielie_zj@163.com

Dr Yu Zhu, Department of Clinical Laboratory, Tianjin Huan $\mathrm{Hu}$ Hospital, Tianjin 300060, P.R. China

E-mail: zhuyutj@126.com

${ }^{*}$ Contributed equally

Key words: alkylglycerone phosphate synthase, glioma, hepatic carcinoma, invasion management (1-2). Invasion is a complex process, involving altered expression of adhesion molecules, proteinase, cytokines and transcriptional factors in tumor cells (3). Therefore, studies on the potential suppressor genes involved in glioma and hepatic carcinoma are required to inhibit invasion and improve cancer treatment efficacy.

Some studies have shown that tumor cells possess higher levels of ether lipids compared with normal cells through the alkyl or alkenyl chain. Certain ether lipids, such as, lysophosphatidic acid-ether (LPAe) or platelet-activating factor-ether (PAFe), have shown certain oncogenic properties. The alkylglycerone phosphate synthase (AGPS) is a critical enzyme for ether lipid synthesis, overexpressing in tumor cells and increasing tumor cell growth and metastasis. Some studies support the fact that AGPS is a pro-metastasis gene, promoting the invasion and metastasis of several types of human cancer (4).

In the present study, we sought to elucidate the effects and potential molecular mechanism of AGPS in suppressing glioma and hepatic carcinoma cell invasion in vitro. A series of glioma and hepatic carcinoma U87 and HepG2 cell lines with knockdown of AGPS was established, and the effects of AGPS on invasion and expression of relevant genes and signal pathways were investigated in vitro.

\section{Materials and methods}

Cell lines and cell culture. Human glioma and hepatic carcinoma cell lines U87 and HepG2 were obtained from the American Type Culture Collection. Cells were grown and maintained in DMEM medium (Life Technologies) supplemented with $10 \%$ fetal bovine serum (Life Technologies) at $37^{\circ} \mathrm{C}$ with $5 \% \mathrm{CO}_{2}$.

Cell transfection and establishment of stable clones. Cells $\left(3 \times 10^{5}\right)$ were plated into a 6-well plate. AGPS shRNA plasmid and empty vector plasmid (Santa Cruz) were transfected into the cells using the Transfection Reagent (Biomiga) according to the manufacturer's instructions. Stable clones were selected with $300 \mu \mathrm{g} / \mathrm{ml}$ of G418 (Life Technologies). Resistant cell clones were harvested and analyzed using western blotting. Cells transfected with shRNA plasmid were designated as the 
AGPS-knockdown group (shRNA group). Cells transfected with empty vectors were used as the negative groups. The parent cells were used as the parent group.

Extraction and quantization of LPA, LPAe and PGE2. Cancer cells were starved in serum-free media for $4 \mathrm{~h}$ to minimize the contribution of serum-derived metabolites. Approximately $1 \times 10^{6}$ cells were washed twice in PBS and harvested by scraping and centrifugation. Cell pellets were flash frozen at $-80^{\circ} \mathrm{C}$. Nonpolar lipid metabolites were extracted and analyzed by LC-MS/MS. Briefly, cell lysis was extracted by $4 \mathrm{ml}$ of mixture of 2 (chloroform): 1 (methanol): 1 PBS with C12:0 dodecylglycerol $(10 \mathrm{nmol})$ and pentadecanoic acid $(10 \mathrm{nmol})$ as internal standards. Organic and aqueous layers were separated by centrifugation. The aqueous layer was acidified by adding $0.1 \%$ formic acid and reextracted by chloroform. The organic layer was dried by $\mathrm{N} 2$ and dissolved in $120 \mu \mathrm{l}$ chloroform and a $10 \mu 1$ aliquot was analyzed by Agilent 6430 LC-MS/MS.

Cells $\left(4 \times 10^{5} / \mathrm{ml}\right)$, were plated in 96-well plates and cultured overnight. The next day, cells were treated with $0.1 \mathrm{ml}$ arachidonic acid (final concentration $15 \mu \mathrm{M}$ ) for $1 \mathrm{~h}$ before collecting the culture medium. PGE2 levels in the medium were determined by PGE2 enzyme immunoassay kits (Cayman Chemical).

Cell adhesion assay. 96-well plates were coated with $25 \mu \mathrm{l}$ $(0.2 \mu \mathrm{g} / \mu \mathrm{l})$ Matrigel overnight at $37^{\circ} \mathrm{C}$ and blocked with $50 \mu \mathrm{l}$ serum-free medium with $2 \% \mathrm{BSA}$ for $1 \mathrm{~h}$ at $37^{\circ} \mathrm{C}$. Cells $\left(4 \times 10^{4}\right)$ in $100 \mu \mathrm{l}$ serum free medium with $0.1 \%$ BSA were added to the well for $1 \mathrm{~h}$ at $37^{\circ} \mathrm{C}$ with $5 \% \mathrm{CO}_{2}$. Cells were washed with PBS and were determined by MTS assay.

Cell invasion assay. The cell invasion activity was assessed by 24-well Transwell chambers (Costar). The inserts contain an $8 \mu \mathrm{m}$ pore size polycarbonate membrane and $25 \mu \mathrm{l}(0.2 \mu \mathrm{g} / \mu \mathrm{l})$ FN (Sigma) was added on the lower surface of the membrane, over which was a thin layer of $50 \mu \mathrm{l}(0.2 \mu \mathrm{g} / \mu \mathrm{l})$ Matrigel (Sigma). Cells were suspended to a final concentration of $2 \times 10^{6}$ cell $/ \mathrm{ml}$ in serum free medium with $0.1 \%$ BSA. Cell suspensions $(100 \mu \mathrm{l})$ were added to the upper compartment and $600 \mu \mathrm{l}$ serum free medium with $0.1 \%$ BSA was added to the lower compartment. Transwell chambers were incubated for $24 \mathrm{~h}$ at $37^{\circ} \mathrm{C}$ with $5 \% \mathrm{CO}_{2}$. Invasive cells on the lower surface of the membrane were stained by $\mathrm{H} \& \mathrm{E}$ and counted by photographing the membrane in five microscopic fields.

Flow cytometry assay. Cells $\left(3 \times 10^{5}\right)$ were plated into a 6-well plate at $37^{\circ} \mathrm{C}$ for $24 \mathrm{~h}$, collected, and fixed by $70 \%$ cold ethanol at $4^{\circ} \mathrm{C}$ overnight. Then, ethanol was removed and the $300 \mu 1 \mathrm{PI}$ $(50 \mu \mathrm{g} / \mathrm{ml})$ with RNase A were added, incubated at $37^{\circ} \mathrm{C}$ in the dark for $30 \mathrm{~min}$. Cell cycle was measured by flow cytometry at $488 \mathrm{~nm}$.

Western blot analysis. Cells were washed with cold PBS and the cell pellets were lysed using the lysis buffer (Beyotime Institute of Biotechnology) for $45 \mathrm{~min}$ on ice. Lysates were centrifuged $\left(15,000 \mathrm{x} \mathrm{g}, 20 \mathrm{~min}, 4^{\circ} \mathrm{C}\right)$, and the supernatants were analyzed to determine the protein concentration. Threefold concentrated SDS sample buffer was added into the cell lysates and boiled for $5 \mathrm{~min}$. Total cell lysates $(50 \mu \mathrm{g})$ and the protein molecular weight standard were electrophoresed on a $12 \%$ SDS-polyacrylamide gel concurrently, and then the proteins were transferred electrophoretically to nitrocellulose membranes. Blots were blocked for $1 \mathrm{~h}$ at room temperature using 5\% milk and were incubated with monoclonal antibody (E-cadherin, 1:800; CD44, 1:800; MMP-2, 1:800; MMP-9, 1:800; cyclin D1, 1:800; Santa Cruz) and mouse monoclonal $\beta$-actin (Sigma, 1:5,000) which was used for protein loading analyses respectively at $4^{\circ} \mathrm{C}$ overnight. Then, the membranes were washed and incubated with HRP substrate for $1 \mathrm{~h}$ at room temperature. The results were visualized using the Immobilon Western HRP Substrate (Millipore).

Real-time PCR assay. The real-time PCR reagents were purchased from Takara and the primers were synthesized by AuGCT Biological Technology Co., Ltd (Beijing, China). SYBR-Green was used to quantify the mRNA level. The PCR reaction was performed under the following conditions: $10 \mathrm{sec}$ at $95^{\circ} \mathrm{C}$, and 40 cycles at $95^{\circ} \mathrm{C}$ for $5 \mathrm{sec}$ and $65^{\circ} \mathrm{C}$ for $34 \mathrm{sec}$ on the ABI Prism 7500 Sequence Detector System. Glyceraldehyde-3-phosphate dehydrogenase (GAPDH) was used for normalization. The primers for the detected genes are listed in Table I.

Luciferase reporter assay. Cells $\left(1 \times 10^{5}\right)$ were plated in a 24-well plate and then transfected using the Transfection Reagent (Biomiga) following the manufacturer's instructions. Cells were co-transfected with promoter-luciferase plasmids (Twist, AP-1 or Snail) and pRL-SV40 (Promega) as an internal control for $24 \mathrm{~h}$. The luciferase reporter assay was performed using the Dual-luciferase Reporter Assay System (Promega) on Berthold TriStar LB 941 (Berthold Technologies, Bad Wildbad, Germany).

Statistical analysis. The data are presented as mean \pm standard deviation (SD). Variance analysis between groups was performed using one-way ANOVA. All data in the study were evaluated with Statistical Package for the Social Sciences software version 10.0. (SPSS Inc.). Differences were considered significant at values of $\mathrm{P}<0.05$.

\section{Results}

Expression of AGPS on establishment and cellular content of LPA, LPAe and PGE2 of stable glioma and hepatic carcinoma cell clones. To explore the role of AGPS in OVCA cells, the human glioma U87 and hepatic carcinoma HepG2 cell lines were used to reconstitute the expression of AGPS via the stable knockdown of AGPS. As shown in Fig. 1A, the AGPS expression level was downregulated in the AGPS-knockdown group compared to the parent and negative groups.

LPA, LPAe and PGE2 are lipids that have been found to be involved in AGPS-mediated cancer pathogenicity. As shown in Fig. 1B, all LPA, LPAe and PGE2 were downregulated in the AGPS-knockdown group compared to the parent and negative groups, demonstrating that in the two cell lines, silencing of AGPS resulted in reduction of LPA, LPAe and PGE2 (Fig. 1B).

Effect of AGPS on adhesion, invasion and cell cycle of glioma and hepatic carcinoma cells. We hypothesized that AGPS 
Table I. Real-time PCR primer sequences.

\begin{tabular}{ll}
\hline Primers & \multicolumn{1}{c}{ Sequence (5'-3') } \\
\hline CD44 & F: TTGATGGACCAATTACCATAACTATTG \\
& R: CGTTCTGTATTCTCCTTTCTGGACAT \\
E-cadherin & F: AGAACGCATTGCCACATACACTC \\
& R: CATTCTGATCGGTTACCGTGATC \\
MMP-2 & F: ACTGCGGTTTTCTCGAATCCA \\
& R: GGTATCCATCGCCATGCTCC \\
MMP-9 & F: CGGCTTGCCCTGGTGCAGT \\
& R: CGTCCCGGGTGTAGAGTCTCTCG \\
cyclin D1 & F: TCTAAGATGAAGGAGACCATC \\
& R: GCGGTAGTAGGACAGGA \\
GAPDH & F: GAAGGTGAAGGTCGGAGTC \\
& R: GAAGATGGTGATGGGATTTC \\
\hline
\end{tabular}

F, forward; R, reverse.

played a role in regulating glioma and hepatic carcinoma cell adhesion and invasion ability. To test this hypothesis, we investigated the effect of AGPS-knockdown in adhesion and invasion assays.

As shown in Fig. 2A, cells of AGPS-knockdown groups show an increased adhesion compared to parent and negative groups cells, suggesting that AGPS was acting as a regulative gene on U87 and HepG2 cell adhesion. We assessed the modulation effect of AGPS on the ability of epithelial tumor cells to invade a reconstituted extracellular matrix (ECM) by cell invasion assay. When cells of AGPS-knockdown groups were grown on Matrigel, a significant increase in the number of invasive cells was observed compared to the parent and negative groups after $24 \mathrm{~h}$ (Fig. 2B). The results suggest that AGPS expression is inversely associated with the invasion ability of glioma and hepatic carcinoma cells in vitro. Cell cycle is also an important factor in tumor metastasis; we found that AGPS-knockdown arrested the cell cycle in the G0/G1 phase (Fig. 2C). Furthermore, we found that there was a decreased expression of cyclin D1 in U87 and HepG2 cells (Fig. 3). Therefore, we considered that cell cycle arrest may be one of the mechanisms through which AGPS regulates tumor invasive potential.

Effect of AGPS on expression of invasion-related genes in vitro. To investigate the relationships between AGPS and expression of invasion-related genes, we examined the expression level of adhesion molecules such as E-cadherin and CD44 in cells. We found that AGPS knockdown promoted the mRNA and protein expression of CD44. In addition, the results demonstrated that the expression of E-cadherin was suppressed in the parent and negative groups but was increased in the AGPS-knockdown group (Fig. 3).

To further investigate the molecular mechanism, we also observed that AGPS had significantly regulated expression levels for MMP-2/9. MMP-2/9 play important roles in cancer invasion. The AGPS-knockdown group exhibited significant
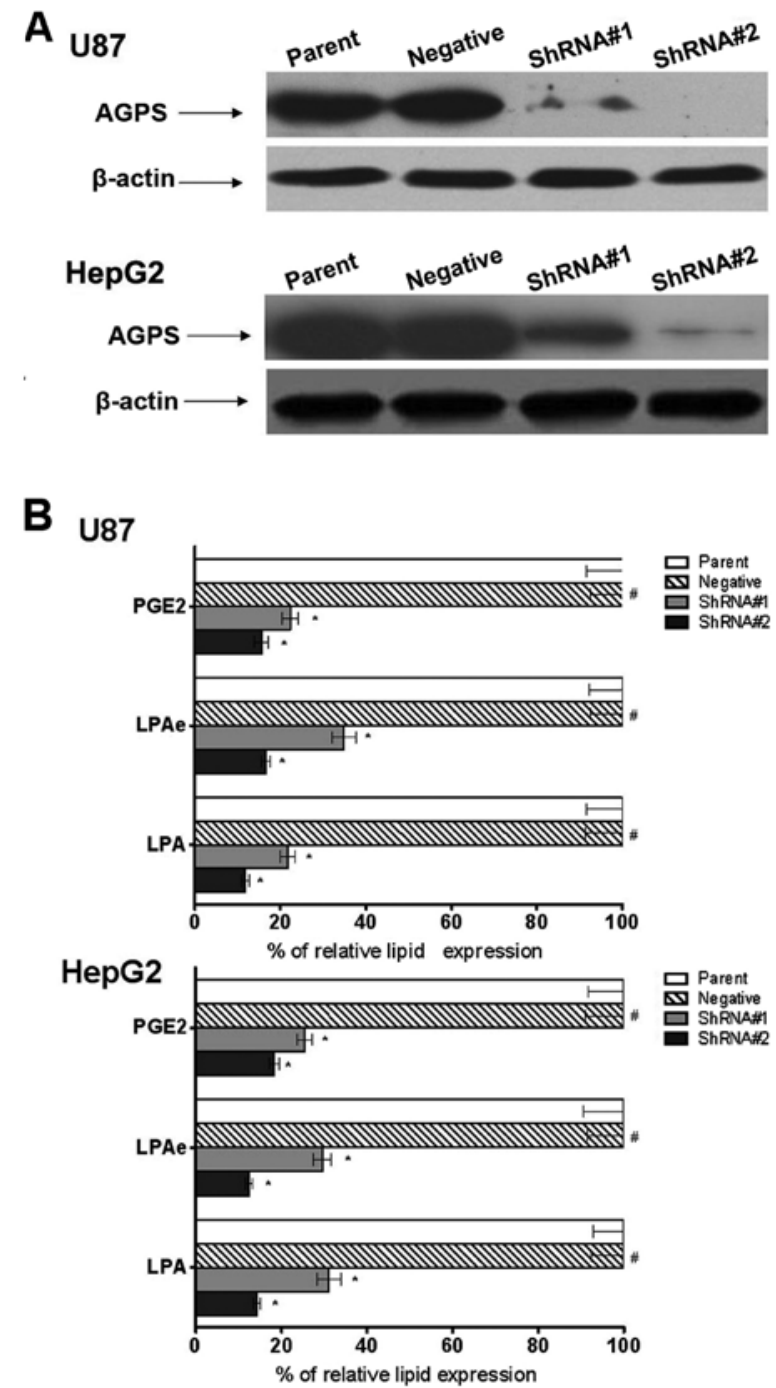

Figure 1. Expression level of AGPS in different clones of stably transfected glioma and hepatic carcinoma cells. (A) Western blot assay showed a decreased AGPS expression in stable AGPS-knockdown human glioma U87 and hepatic carcinoma HepG2 cell lines (shRNA\#1 and shRNA\#1) compared with the parent and negative groups. $\beta$-actin was used as an internal control. (B) The LC-MS/MS and enzyme immunoassay assay showed a decreased cellular expression of LPA, LPAe and PGE2 in AGPS-knockdown human glioma U87 and hepatic carcinoma HepG2 cell lines (shRNA\#1 and shRNA\#1) compared with the parent and negative groups. Bars, mean $\pm \mathrm{SD}$ ${ }^{\#} \mathrm{P}>0.05$ compared to the control group, ${ }^{*} \mathrm{P}<0.05$ compared to the control group, $\mathrm{n}=10$.

downregulation of MMP-2/9 at the mRNA and protein levels compared to the parent and negative groups, as shown in Fig. 3. This suggested a regulatory effect of AGPS on the expression of MMP in glioma and hepatic carcinoma cells.

Effect of AGPS on the MAPK signaling pathway in glioma and hepatic carcinoma cells. The MAPK signaling pathway is an important cell signaling pathway, involved in the regulation of many fundamental cellular processes. As shown in Fig. 4A, AGPS-knockdown reduced phosphorylation of both MEK and ERK compared with the parent and negative groups; meanwhile, total MEK and ERK levels remained unchanged.

Twist, AP-1 and Snail are considered to play important roles in tumor development. In this study, using the luciferase 
A
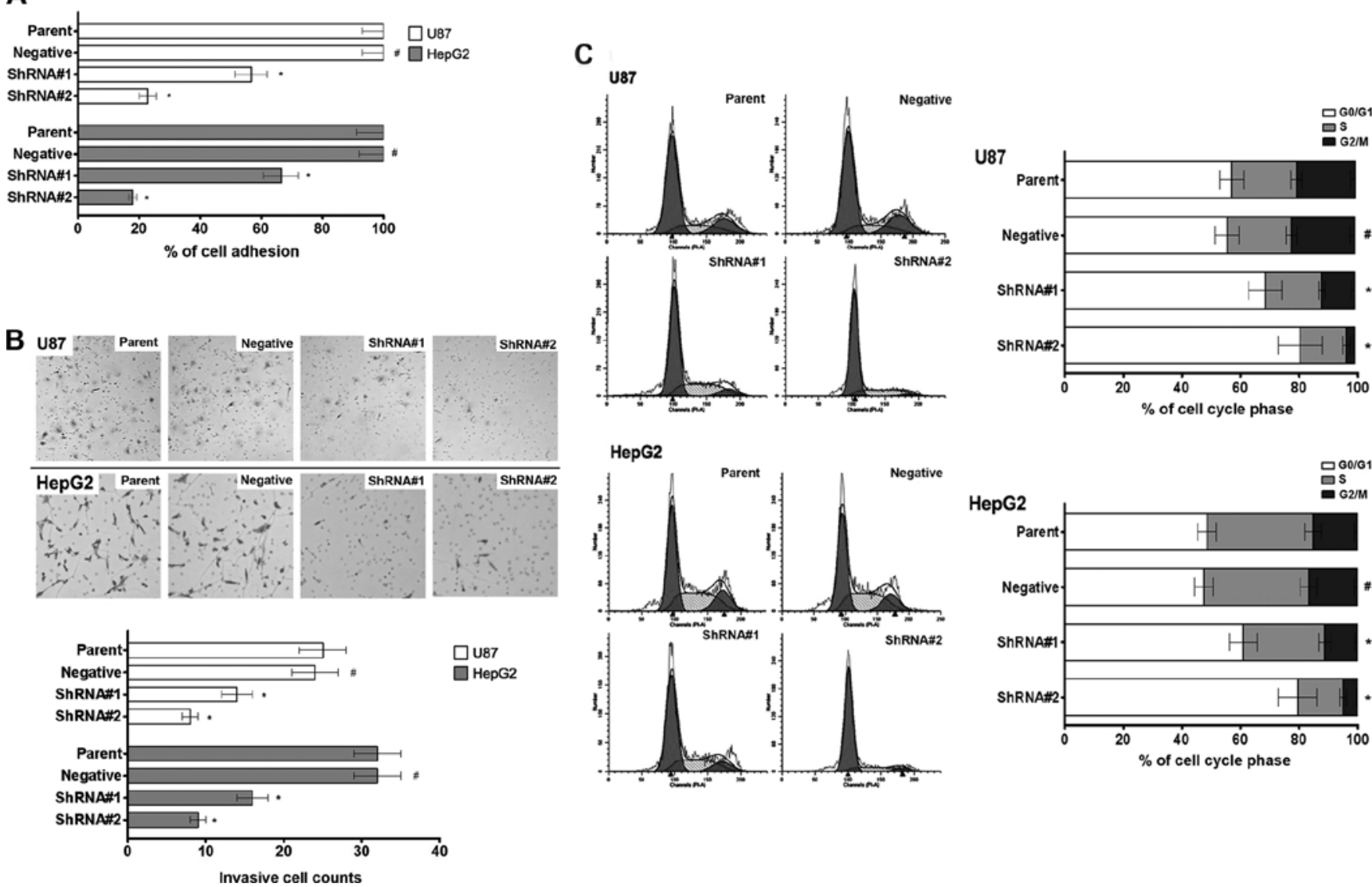

Figure 2. Effect of AGPS on adhesion, invasion and cell cycle of glioma and hepatic carcinoma cells. (A) MTS assay revealed a decreased adhesion ability in AGPS-knockdown human glioma U87 and hepatic carcinoma HepG2 cell lines (shRNA\#1 and shRNA\#1) compared with parent and negative groups. Bars, mean \pm SD. ${ }^{*} \mathrm{P}>0.05$ compared to the control group, ${ }^{*} \mathrm{P}<0.05$ compared to the control group, $\mathrm{n}=10$. (B) The invasiveness assay revealed a decreased invasiveness ability in AGPS-knockdown human glioma U87 and hepatic carcinoma HepG2 cell lines (shRNA\#1 and shRNA\#1) compared with parent and negative groups. Bars, mean $\pm \mathrm{SD}$. " $\mathrm{P}>0.05$ compared to the control group, ${ }^{*} \mathrm{P}<0.05$ compared to the control group, $\mathrm{n}=3$. (C) The flow cytometry assay revealed a G0/G1 phase arrest in AGPS-knockdown human glioma U87 and hepatic carcinoma HepG2 cell lines (shRNA\#1 and shRNA\#1) compared with parent and negative groups. Bars, mean \pm SD. ${ }^{*} \mathrm{P}>0.05$ compared to the control group, ${ }^{*} \mathrm{P}<0.05$ compared to the control group, $\mathrm{n}=3$.

reporter assay, we investigated the effects of AGPS on the transcriptional activity of Twist, AP-1 and Snail. As shown in Fig. 4B, compared to the parent and negative groups, AGPSknockdown inhibited the transcriptional activity of Twist, Snail and AP-1.

\section{Discussion}

Tumor-related mortality is primarily due to the invasion progression of tumor cells and increasing evidence supports the important role of invasion in cancer progression $(5,6)$. Thus, to improve the clinical outcome, it is essential to understand the mechanism of AGPS-knockdown inhibition in this complex processes.

The research and development of invasion-related genes is one of the most active fields in cancer research. The metabolic enzyme alkylglycerone phosphate synthase (AGPS) is a critical step in the synthesis of ether lipids and is upregulated across multiple types of tumor. We examined the effect of AGPS-knockdown on the potential of invasion of these cells, and investigated the regulation mechanism and roles of the AGPS-regulated invasion in glioma and hepatic carcinoma cells.
Invasion is a program of the development of tumor cells by the altered expression of cellular lipids and genes and increased invasion was potentially reported as the key step towards cancer aggravation (7). We found that AGPS-knockdown could suppress expression of cellular lipids such as LPA, LPAe and PGE2, adhesion and invasion of glioma U87 and hepatic carcinoma HepG2 cells. To further understand the mechanism, we investigated a series of key factors in the process of invasion. Cell cycle is a key step of tumor invasion, the results showed that AGPS-knockdown could arrest cell cycle in the G0/G1 phase and downregulated the expression of cyclin D1 in tumor cells. CD44 has numerous functions involved in tumor adhesion, growth, differentiation and resistance to apoptosisinducing chemotherapeutic agents. Suppression of adhesion molecule expression such as E-cadherin and increased cell mobility were reported to be the key steps toward cancer metastasis. MMP-2/9 degraded the components of the basement membrane and are strongly implicated in the invasion of many types of tumor (8-12). Our study clearly demonstrated that AGPS-knockdown improved the expression of E-cadherin, and downregulated the expression of CD44 in tumor cells. We further demonstrated the regulatory role of AGPS in invasion through regulating MMP-2/9 gene expression. These results 
A
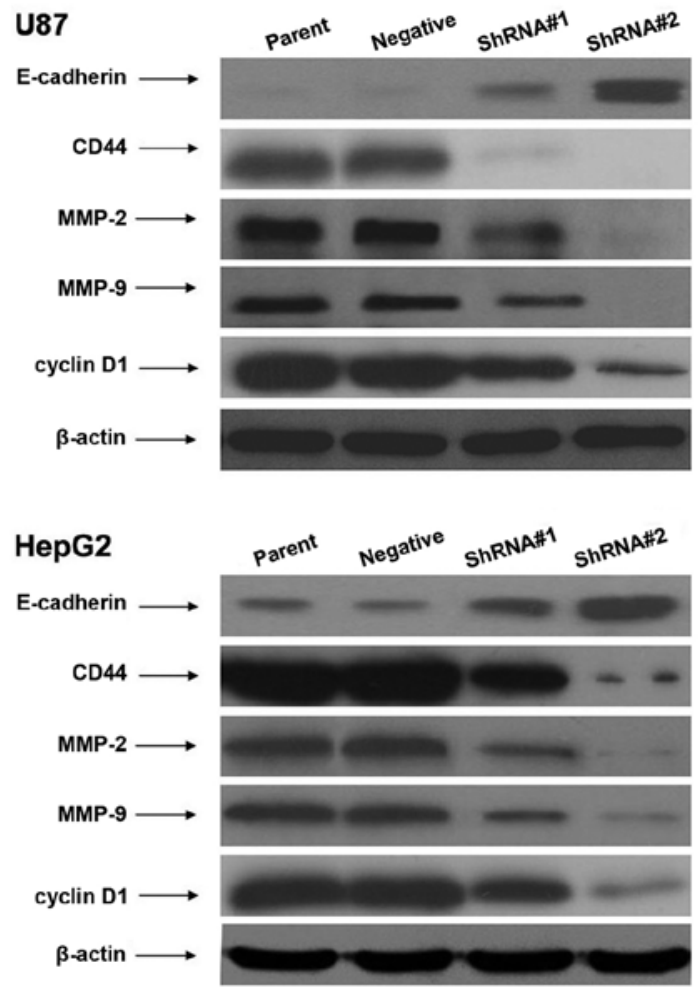

B U87
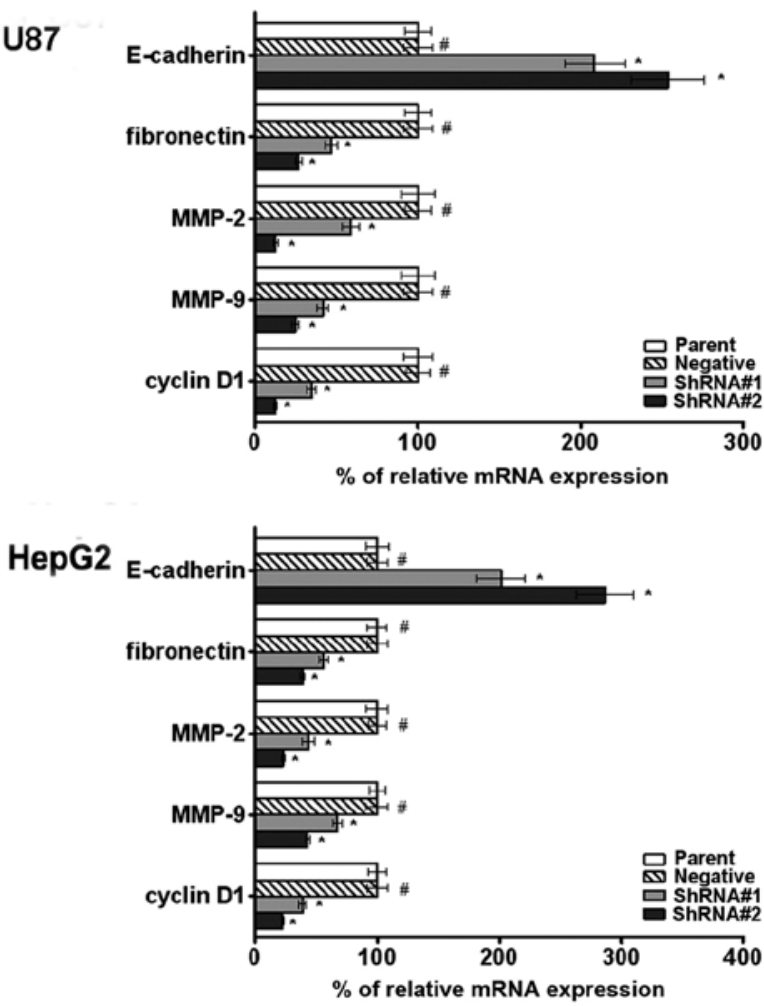

Figure 3. Effect of AGPS on the expression of invasion-related genes of glioma and hepatic carcinoma cells in vitro. (A) Western blot assay showed an increased protein expression of E-cadherin and a decreased protein expression of CD44, MMP-2/9 and cyclin D1 in AGPS-knockdown human glioma U87 and hepatic carcinoma HepG2 cell lines (shRNA\#1 and shRNA\#1) compared with parent and negative groups. $\beta$-actin was used as an internal control. (B) RT-PCR assay showed an increased mRNA expression of E-cadherin and a decreased mRNA expression of CD44, MMP-2/9 and cyclin D1 in AGPS-knockdown human glioma U87 and hepatic carcinoma HepG2 cell lines (shRNA\#1 and shRNA\#1) compared with parent and negative groups. GAPDH was used as an internal control for loading. Bars, mean $\pm \mathrm{SD} .{ }^{*} \mathrm{P}>0.05$ compared to the control group, ${ }^{*} \mathrm{P}<0.05$ compared to the control group, $\mathrm{n}=10$.
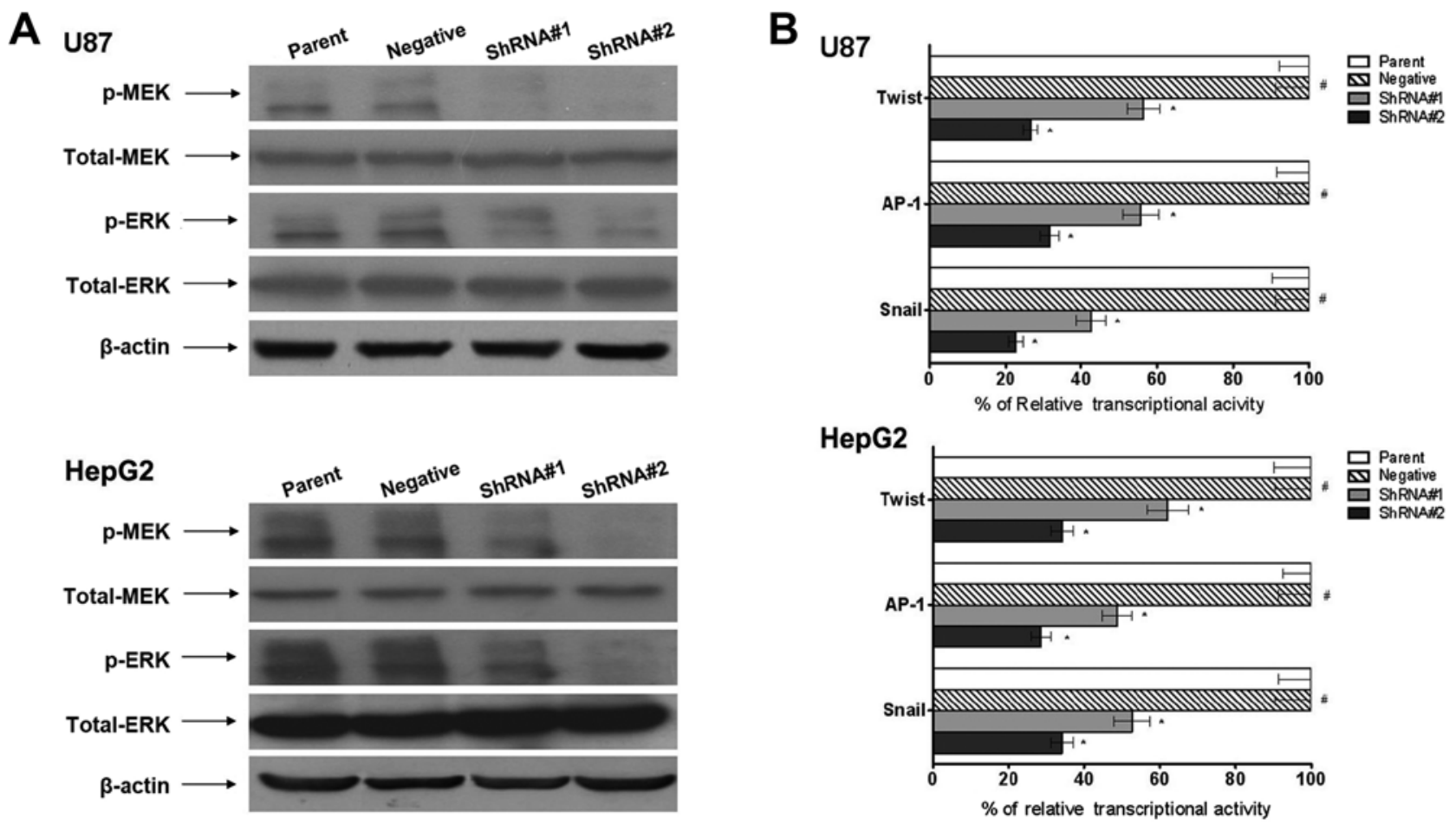

Figure 4. Effect of AGPS on the signaling pathway of glioma and hepatic carcinoma cells in vitro. (A) Western blot assay showed a decreased phosphorylation of both MEK and ERK in AGPS-knockdown human glioma U87 and hepatic carcinoma HepG2 cell lines (shRNA\#1 and shRNA\#1) compared with parent and negative groups. Furthermore, total MEK and ERK levels remained unchanged. $\beta$-actin was used as an internal control. (B) Report gene assay showed a decreased transcriptional activity of Twist, AP-1, and Snail in AGPS-knockdown human glioma U87 and hepatic carcinoma HepG2 cell lines (shRNA\#1 and shRNA\#1) compared with parent and negative groups. Bars, mean $\pm \mathrm{SD} .{ }^{\#} \mathrm{P}>0.05$ compared to the control group, ${ }^{*} \mathrm{P}<0.05$ compared to the control group, $\mathrm{n}=10$. 
strongly suggest that AGPS plays an important role in invasion through the modulation of invasion-related genes.

The MAPK signaling pathway is involved in the regulation of many fundamental cellular processes, including proliferation, differentiation, survival and cell death, as well as controlling the expression of a number of pro-metastasis genes. Twist, AP-1, and Snail are the transcription factors required for the upregulation of a large number of genes encoding proteins important for invasion in cancer (13-16). We found that AGPS-knockdown reduced activity of the MAPK signaling pathway and transcription activity of Twist, AP-1, and Snail, and we considered that it may be a key mechanism for AGPS to regulate the invasion of tumor cells.

In summary, our study showed that AGPS is an invasion promoter of glioma and hepatic carcinoma. The decreased AGPS expression was correlated with decreased invasion potential by the modulation of the MAPK signaling pathway and activities of transcriptional factors. Therefore, we consider AGPS to be a potential molecular target for cancer invasion.

\section{Acknowledgements}

This study was supported by The Fund of the Health Bureau of Tianjin (Grant No. 2013KY17) and Tianjin Research Program of Application Foundation and Advanced Technology (Grant No. 14JCQNJC12000).

\section{References}

1. Zhang H, Nie W, Zhang X, Zhang G, Li Z, Wu H, Shi Q, Chen Y, Ding Z, Zhou X and Yu R: NEDD4-1 regulates migration and invasion of glioma cells through CNrasGEF ubiquitination in vitro. PLoS One 12: e82789, 2013.

2. Li Y, Shi X, Zhang J, Zhang X and Martin RC: Hepatic protection and anticancer activity of curcuma: A potential chemopreventive strategy against hepatocellular carcinoma. Int J Oncol 2: 505-513, 2014.

3. Kahlert UD, Nikkhah G and Maciaczyk J: Epithelial-tomesenchymal(-like) transition as a relevant molecular event in malignant gliomas. Cancer Lett 2: 131-138, 2013.

4. Benjamin DI, Cozzo A, Ji X, Roberts LS, Louie SM, Mulvihill MM, Luo K and Nomura DK: Ether lipid generating enzyme AGPS alters the balance of structural and signaling lipids to fuel cancer pathogenicity. Proc Natl Acad Sci USA 37: 14912-14917, 2013.
5. Liu Y, Zhao Y, Ju Q, Chen L, Li F, Zhou G, Xie P, Li G and $\mathrm{Li}$ Y: Molecular clone and functional study of a novel hepatoma associated gene. Int J Oncol 3: 1105-1112, 2013.

6. Zhu Y, Yang P, Wang Q, Hu J, Xue J, Li G, Zhang G, Li X, Li W, Zhou C, Zhao M and Wang D: The effect of CXCR4 silencing on epithelial-mesenchymal transition related genes in glioma U87 cells. Anat Rec (Hoboken) 12: 1850-1856, 2013.

7. Chen S, Wang J, Gou WF, Xiu YL, Zheng HC, Zong ZH, Takano Y and Zhao Y: The involvement of RhoA and Wnt-5a in the tumorigenesis and progression of ovarian epithelial carcinoma. Int J Mol Sci 12: 24187-24199, 2013.

8. Chen X, Xiao W, Chen W, Luo L, Ye S and Liu Y: The epigenetic modifier trichostatin A, a histone deacetylase inhibitor, suppresses proliferation and epithelial-mesenchymal transition of lens epithelial cells. Cell Death Dis 4: e884, 2013.

9. Koay MH, Crook M and Stewart CJ: Cyclin D1, E-cadherin and beta-catenin expression in FIGO Stage IA cervical squamous carcinoma: diagnostic value and evidence for epithelial-mesenchymal transition. Histopathology 6: 1125-1133, 2012.

10. La Monica S, Caffarra C, Saccani F, Galvani E, Galetti M, Fumarola C, Bonelli M, Cavazzoni A, Cretella D, Sirangelo R, Gatti R, Tiseo M, Ardizzoni A, Giovannetti E, Petronini PG and Alfieri RR: Gefitinib inhibits invasive phenotype and epithelialmesenchymal transition in drug-resistant NSCLC cells with MET amplification. PLoS One 10: e78656, 2013.

11. Ren D, Wang M, Guo W, Zhao X, Tu X, Huang S, Zou X and Peng X: Wild-type p53 suppresses the epithelial-mesenchymal transition and stemness in PC-3 prostate cancer cells by modulating miR-145. Int J Oncol 4: 1473-1481, 2013.

12. Hsieh YS, Chu SC, Hsu LS, Chen KS, Lai MT, Yeh CH and Chen PN: Rubus idaeus L. reverses epithelial-to-mesenchymal transition and suppresses cell invasion and protease activities by targeting ERK1/2 and FAK pathways in human lung cancer cells. Food Chem Toxicol 62: 908-918, 2013.

13. Li NY, Weber CE, Wai PY, Cuevas BD, Zhang J, Kuo PC and Mi Z: An MAPK-dependent pathway induces epithelial-mesenchymal transition via Twist activation in human breast cancer cell lines. Surgery 2: 404-410, 2013.

14. Ferraro A, Mourtzoukou D, Kosmidou V, Avlonitis S, Kontogeorgos G, Zografos G and Pintzas A: EZH2 is regulated by ERK/AKT and targets integrin alpha2 gene to control epithelialmesenchymal transition and anoikis in colon cancer cells. Int J Biochem Cell Biol 2: 243-254, 2013.

15. Pakala SB, Singh K, Reddy SD, Ohshiro K, Li DQ, Mishra L and Kumar R: TGF- $\beta 1$ signaling targets metastasis-associated protein 1, a new effector in epithelial cells. Oncogene 19: 2230-2241, 2011

16. Tsubaki M, Komai M, Fujimoto S, Itoh T, Imano M, Sakamoto K, Shimaoka H, Takeda T, Ogawa N, Mashimo K, Fujiwara D, Mukai J, Sakaguchi K, Satou T and Nishida S: Activation of $\mathrm{NF}-\kappa \mathrm{B}$ by the RANKL/RANK system up-regulates snail and twist expressions and induces epithelial-to-mesenchymal transition in mammary tumor cell lines. J Exp Clin Cancer Res 1: 62, 2013. 